\title{
(3) IEB
}

Institut

d'Economia

de Barcelona

\section{Document de treball de l’IEB 2014/6}

\section{DIFFERENCE-FORM GROUP CONTESTS}

María Cubel, Santiago Sanchez-Pages 


\title{
DIFFERENCE-FORM GROUP CONTESTS
}

\author{
María Cubel, Santiago Sanchez-Pages
}

The Barcelona Institute of Economics (IEB) is a research centre at the University of Barcelona (UB) which specializes in the field of applied economics. The IEB is a foundation funded by the following institutions: Applus, Abertis, Ajuntament de Barcelona, Diputació de Barcelona, Gas Natural and La Caixa.

\author{
Postal Address: \\ Institut d'Economia de Barcelona \\ Facultat d'Economia i Empresa \\ Universitat de Barcelona \\ C/ Tinent Coronel Valenzuela, 1-11 \\ (08034) Barcelona, Spain \\ Tel.: + 34934034646 \\ ieb@ub.edu \\ http://www.ieb.ub.edu
}

The IEB working papers represent ongoing research that is circulated to encourage discussion and has not undergone a peer review process. Any opinions expressed here are those of the author(s) and not those of IEB. 


\title{
DIFFERENCE-FORM GROUP CONTESTS *
}

\author{
María Cubel, Santiago Sanchez-Pages
}

\begin{abstract}
Contests are situations in which a set of agents compete for a valuable object, rent or award. The present paper analyzes difference-form group contests, that is, contests fought among groups and where their probability of victory depends on the difference of their effective efforts. First, we show that the non-existence of pure-strategy equilibria and the monopolization results obtained in previous analysis of difference-form contests rest critically on the assumption of a linear cost of effort. Under exponential costs, we show that pure strategy equilibria exist in a large set of cases and that more than one group can expend positive effort in equilibrium. Second, we show that inequality of valuations of victory within groups hinders their chances of prevailing in the contest. If possible; members may find beneficial to engage in progressive redistribution within their group.
\end{abstract}

JEL Codes: D31, D63, D72, D74

Keywords: Contests, contest success function, inequality, redistribution

María Cubel

Dept. of Public Economics \& IEB

Universitat de Barcelona

Av Diagonal 690

08034 Barcelona (Spain)

E-mail: cubel@ub.edu

\author{
Santiago Sanchez-Pages \\ Dept. of Economic Theory \& Edinburgh \\ School of Economics \\ Universitat de Barcelona \\ Av Diagonal 690 \\ 08034 Barcelona (Spain) \\ E-mail: sanchez.pages@gmail.com
}

\footnotetext{
* L We thank Luis Corchón, Wolfgang Leininger, John Morgan, Petros Sekeris, Alberto Vesperoni and audiences at Edinburgh, NEPS and the Young Researchers Workshop on Contests and Tournaments for their useful suggestions and comments. All remaining errors are completely ours. Both authors acknowledge financial support from the Spanish Ministry for Science and Innovation research grant ECO2012-33243.
} 


\section{Introduction}

Contests are present in many areas of human affairs. In interstate and civil wars, patent races, advertising or sport competitions, a set of actors strive to obtain an object or honour that will award them some benefits. In these struggles, contenders often expend staggering amounts of resources. Economists are naturally interested in contests both because of their allocative implications and because of the impact of the intensity of these competitions on social welfare. ${ }^{1}$

Despite its relevance and ubiquitous nature it is only recently that contest theory has become part of mainstream Economics. One important reason for this has been the great reliance of contest theory on a particular construct: The Contest Success Function (Hirshleifer, 1989). This function is a mapping from the efforts made by contenders into their probability of attaining victory or, under risk neutrality, to their share of the contested object. However, the CSF has often been seen as too much of a black-box. For instance, the widely-used Tullock form (Tullock, 1967) under which winning probabilities (or shares) depend on relative efforts may seem sensible but there is no a priori reason why it should govern the wide array of contests listed above. Therefore, the predictions of contests models could be seen as too reliant on (at first glance) very specific functional forms rather than on sound economic principles.

This view is somehow unfair for two reasons: Firstly, because there are other areas of Economics such as production theory where very specific functional forms are often assumed. Secondly, because in the last few years there has been an active and fruitful strand of the literature which has provided a wide variety of foundations to the most frequently employed CSFs. ${ }^{2}$ Other contributions have studied the econometric estimation of these functions. ${ }^{3}$ As a result, economists have now at their disposal a growing menu of wellfounded CSFs to chose from when studying a particular contest. The issue then becomes which type of CSF is better suited to each application.

One family of contests assumes that winning probabilities depend on the difference between the effective efforts of the contenders. These differenceform contests, introduced in Hirshleifer (1989; 1991), were first explored by Baik (1998) and Che and Gale (2000). One distinguished feature of

\footnotetext{
${ }^{1}$ For excellent surveys of the contest literature see Corchón (2007) and Konrad (2009).

${ }^{2}$ These characterizations fall into four main categories: Axiomatic, stochastic, optimally-designed and microfounded (Jia, Skaperdas and Vaidya, 2013).

${ }^{3}$ For a detailed discussion of the econometric issues involved in the estimation of CSFs see Jia and Skaperdas (2011) and Jia et al. (2013).
} 
the difference-form CSFs is that if contenders expend zero effort they can still enjoy a positive winning probability. Hirshleifer (1991) argues that this feature applies very well to contests with important frictions, such as incomplete information, exhaustion or rugged terrain. Naval combat is also prone to display this feature: severe storms almost obliterated the Persian navy in $480 \mathrm{BC}$, the Mongol navy in 1281 and the Spanish Armada in 1588; as a result, Greece, Japan and the England respectively prevailed by making virtually no defensive effort. Hirshleifer (2000) also argues that the difference-form CSF is well-suited to model union-management conflict; even when the union is in a overwhelmingly dominant position, it will refrain from imposing draconian terms on the management because it is in its interest to keep the firm in business. We also see the difference-form to be well suited for the study of influence activities within organizations (Milgrom, 1988) and within federations (Wärneryd, 1998). Under the interpretation of the CSF as a share, it is difficult to imagine that exerting no influence effort precludes an employee from receiving any rents from her employer or a region from receiving any transfer from the federal government.

In addition, difference-form CSFs have been shown to emerge naturally in a number of settings. Gersbach and Haller (2009) show that a simple difference-form CSF is the result of intra-household bargaining when partners must decide how much time to devote to themselves or to their partner. Corchon and Dahm (2010) microfound a particular type of difference-form CSF as the result of a game where contenders are uncertain about the type of the external decider; by interpreting the CSF as a share, they also show that the difference-form coincides with the claim-egalitarian solution in bargaining. Corchon and Dahm (2011) obtain this form as the result of a problem where the contest designer is unable to commit to a specific CSF once contenders have already exerted their efforts. Skaperdas and Vaydia (2012) show that the difference-form CSF can be derived in a Bayesian framework in which contenders produce evidence stochastically in order to persuade an audience of the correctness of their respective views. Finally, Polishchuk and Tonis (2013) show that a non linear difference-form CSF is the result of using a mechanism design approach when contestants have private information over their valuation of victory. In summary, it is fair to conclude that difference-form contests are both well-founded and well suited for a number of relevant applications.

The present paper offers a systematic study of difference-form group contests, that is, contests fought among groups whose winning probabilities depend on the difference between their effective efforts. This type of group contests have not been studied before in the literature. 
First, we perform the equilibrium analysis of the difference-form group contests. We employ a specific functional form of the CSF. In this form, the impact function of the groups mapping their efforts into effective efforts is reminiscent of the index of absolute inequality introduced by Kolm (1976a,b) and characterized by Blackorby and Donaldson (1980). We also assume the cost function of efforts to be exponential; this functional form, to the best of our knowledge, has not been employed in the contest literature before. This function encompasses as a particular case the case of linear costs, the only one considered so far in the study of difference-form contests. We start by analyzing the case of homogeneous groups, that is, when members' valuations of victory are the same within each group. We show that the non-existence of pure strategy equilibria and the monopolization results obtained in the literature depend critically on the linearity assumption. Monopolization (a term coined by Nitzan, 1991) refers to the feature that in equilibrium at most one contender is active, i.e. expends positive effort. This feature is a well known result in the contest literature. However, we show that as soon as the cost function becomes strictly convex more than one group can be active in equilibrium. Still, it can be the case that not all groups are active. ${ }^{4}$ This depends on whether the valuation of the victory by the group is above a certain activity threshold. One force driving this result is that, as mentioned above, groups can enjoy a positive winning probability even if inactive. Only if they value victory intensely enough will they become active.

Second, we consider the case of heterogeneous groups. Our purpose there is two answer two questions: 1) Are more egalitarian groups relatively more successful in these contests?; and 2) would groups benefit from internal redistribution? This case is quite complex to solve but the picture that emerges from the analysis shows that egalitarianism is never bad for the group. However, redistribution that takes place below the activity threshold may have no impact on the chances of victory of the group. Progressive redistribution above that line or such that some inactive members become active does indeed enhance the prospects of the group in the contest.

The remainder of the paper is as follows: In Section 2 we present a family of difference-form group contests. Section 3 and 4 analyze the cases of homogeneous and heterogeneous group valuations respectively. Section 5 tackles the issue of inequality and redistribution within groups. We summarize and offer some further remarks in Section 6.

\footnotetext{
${ }^{4}$ This is similar to the phenomenon of oligopolization which emerges in group contests under the Tullock CSFs and linear costs (Hillman and Riley, 1989; Ueda, 2002).
} 


\section{The contest game}

Let us consider a society divided in $K \geq 2$ disjoint groups formed by a number $n_{k} \geq 1$ of individuals each. The total number of individuals in society is $n$. Denote the set of groups by $\mathbb{K}$. These $K$ groups are in competition. They are engaged in a contest which can have a sole winner. Members of these groups can expend non-negative effort in order to help their group to win the contest. Depending on the type of contest, these efforts can be money, time or weapons. Denote by $\mathbf{x}_{k}=\left\{x_{1 k}, \ldots, x_{n_{k}}\right\}$ the vector of efforts in group $k$ and by $\mathbf{x}$ the vector $\left(\mathbf{x}_{1}, \ldots, \mathbf{x}_{K}\right)$.

Efforts determine the winning probability of each group according to a Contest Success Function (CSF) denoted by $p_{k}: \mathbb{R}_{+}^{n} \rightarrow \mathbb{R}_{+}$. Under risk neutrality $p_{k}(\mathbf{x})$ can be thought of as the share of the prize associated to victory that group $k$ obtains. However, for most of the paper, we will favor the former interpretation of the CSF.

The constest success function (CSF) that we use is defined as follows

$$
p_{k}(\mathbf{x})=\max \left\{\min \left\{\frac{1}{K}+h_{k}\left(\mathbf{x}_{k}\right)-\frac{1}{K} \sum_{l=1}^{s} h_{l}\left(\mathbf{x}_{l}\right), 1\right\}, 0\right\} \quad \text { for any } \mathbf{x}
$$

where $h_{k}(\cdot)$ is called the impact funtion of group $k$ and it is given by

$$
h_{k}\left(\mathbf{x}_{k}\right)=\ln \left(\frac{1}{n_{k}} \sum_{i=1}^{n_{k}} e^{-\gamma_{k} x_{i k}}\right)^{-\frac{\beta}{\gamma_{k}}} \quad \text { for } \gamma_{k} \geq 0, \beta>0 .
$$

The difference-form group CSF in (1) relates the success of a group to the difference between its impact and the average impact of all the groups involved in the contest. If its impact is above (below) the average, its winning probability is above (below) the winning probability the group would be awarded under a fair lottery.

The CSF in (1) generalizes the difference-form function analyzed in Che and Gale (2000) to the case of multi-group contests. Similar CSFs are microfounded in Corchón and Dahm (2010), Skaperdas and Vaidya (2012) and Polishchuk and Tonis (2013).

The impact function (2) is inspired by the measures of absolute inequality introduced by Pollak (1971) and Kolm (1976a,b) and axiomatized by Blackorby and Donaldson (1980). The parameter $\beta$ can be seen as a measure of the returns to scale of effort. On the other hand, the parameter 
$\gamma_{k} \in[0, \infty)$ measures the complementarity of exponential efforts ${ }^{5}$. When $\gamma_{k}$ approaches zero the impact of a group becomes just the sum of its members' efforts, i.e. $h\left(\mathbf{x}_{k}\right)=\sum_{i=1}^{n_{k}} x_{i k}$; this is the linear case considered in Che and Gale (2000) and Corchon and Dahm (2011). When $\gamma_{k} \rightarrow \infty$ then $h\left(\mathbf{x}_{k}\right)=n_{k} \cdot \min \left\{x_{1 k}, \ldots, x_{n_{k} k}\right\}$, which corresponds to the weakest-link technology explored in contests of the ratio form by Lee (2012). ${ }^{6}$ The latter case is the only one in which the function $h_{k}\left(\mathbf{x}_{k}\right)$ is not strictly increasing. Finally, observe that we are assuming our CSF to be anonymous within groups (Münster, 2009). That is, all members of all groups are equally efficient in transforming efforts into impact in the contest.

Let us now study the strategic interaction of the $K$ groups in our society which are engaged in a contest. Victory in this confrontation can be interpreted as providing the group with a prize, territory, pool of resources or the right to implement a particular policy. Group members are heterogeneous in their valuation of the victory of their group. Denote by $y_{i k}$ the payoff that a member $i$ of group $k$ obtains in case her group attains victory in the contest. Depending on the interpretation of victory, the profile of valuations $\mathbf{y}_{k}=\left(y_{1 k}, \ldots, y_{n_{k} k}\right)$ can be seen as a binding agreement on the distribution of the object being contested (as in Cubel and Sanchez-Pages, 2013) or as the intensity of members' feelings about the policy the group will implement in case it prevails (as in Esteban and Ray, 2011). We assume the valuation of defeat in the contest to be equal to zero.

Plugging the impact function (2) in (1) yields the group winning probability

$$
p_{k}=\frac{1}{K}+\ln \left(\frac{1}{n_{k}} \sum_{i=1}^{n_{k}} e^{-\gamma_{k} x_{i k}}\right)^{-\beta \frac{n_{k}^{\delta}}{\gamma_{k}}}-\frac{1}{K} \sum_{l=1}^{s} \ln \left(\frac{1}{n_{l}} \sum_{i=1}^{n_{l}} e^{-\gamma_{l} x_{i l}}\right)^{-\beta \frac{n_{l}^{\delta}}{\gamma_{l}}} .
$$

Note that a group can have a positive probability of victory even if all its members remain inactive.

Members' efforts are costly. Their cost is given by the following exponential cost function:

$$
c\left(x_{i k}\right)=\frac{e^{\phi x_{i k}}-1}{\phi} \quad \text { for } \phi>0 .
$$

The parameter $\phi$ measures the convexity of the cost, or in other words, the speed at which the marginal cost of effort increases. To the best of our

\footnotetext{
${ }^{5}$ Impact functions which allow for different degrees of complementarity were first used by Kolmar and Rommeswinkel (2013).

${ }^{6}$ Weakest-link type of technologies in collective action problems were first considered by Hirshleifer (1983).
} 
knowledge we are the first to employ this family of cost functions. Note that it encompasses as a particular case the linear cost function employed in all the previous studies of contests with difference-form CSF, i.e. $\phi \rightarrow 0$. For any value of $\phi$, however, observe that $c^{\prime}(0)=1$. As we will see below, this is the ultimate reason why players can remain inactive in a pure-strategy equilibrium.

Summarizing, the payoff of a member $i$ of group $k$ is given by

$$
u_{i k}(\mathbf{x})=p_{k}(\mathbf{x}) y_{i k}-c\left(x_{i k}\right) .
$$

We now look for the Nash Equilibrium in pure strategies of this contest game where members decide how much effort to contribute to the success of their group whilst taking as given the effort of outsiders and their fellow group members. We will refer to this simply as the equilibrium.

Note on linear efforts: The contest game presented above with exponential efforts is equivalent to a game with linear efforts where $\varkappa_{i k}=e^{x_{i k}}$ imposing the restriction of $\varkappa_{i k}>1 .^{7}$ The impact function in (2) would then become the log of a CES function aggregating members' efforts. Contribution to the contest would then require a minimum investment. This would correspond for instance to armed conflicts in the Antiquity and the Middle Age where soldiers where supposed to show up in the battlefield with their own equipment. That of course meant that typically only the wealthier members of society could afford to fight war (Finer, 1975).

\section{Homogeneous groups}

As a first step in our analysis, let start by exploring the case of homogeneous groups, that is, the case where all members of the same group have the same valuation of victory, denoted by $y_{k}$. This encompasses as a particular case the case of indidividual contests, i.e. $n_{k}=1$ for all $k$. As expected then, under linearity of the cost function we obtain the monopolization result found by Baik (1998) and Che and Gale (2000): At most one group is inactive in equilibrium. When the cost is strictly convex, though, it is possible to have more than one group active in equilibrium, even all of them.

Let us first write down the FOC resulting from maximizing the payoff function (4) and assuming that in equilibrium no group wins for certain:

$$
\frac{\partial u_{i k}}{\partial x_{i k}}=\beta \frac{K-1}{K} \frac{e^{-\gamma_{k} x_{i k}}}{\sum_{j=1}^{n_{k}} e^{-\gamma_{k} x_{j k}}} n_{k}^{\delta} y_{i k}-e^{\phi x_{i k}}=0 .
$$

\footnotetext{
${ }^{7}$ We thank Alberto Vesperoni for pointing this equivalence to us.
} 
Note that the SOC condition for the problem ensures its concavity:

$$
\frac{\partial^{2} u_{i k}}{\partial^{2} x_{i k}}=-\beta \frac{K-1}{K} \frac{\gamma_{k} e^{-\gamma_{k} x_{i k}} \sum_{j \neq i} e^{-\gamma_{k} x_{j k}}}{\left(\sum_{j=1}^{n_{k}} e^{-\gamma_{k} x_{j k}}\right)^{2}} n_{k}^{\delta} y_{i k}-\phi e^{\phi x_{i k}}<0 .
$$

The marginal benefit of exerting effort is thus decreasing. This feature will play an important role in our characterization of the equilibrium.

3.1: Linear cost: Let us assume, as the rest of the literature on differenceform contests, that the cost of effort is linear, i.e. $\phi=0$. For the sake of exposition we will assume for the rest of the paper the case $\delta=0$. It will be useful to denote $\widetilde{y}_{k}=\frac{y_{k}}{n_{k}}$. Without loss of generality, let us index groups in society decreasingly in their value of $\widetilde{y}_{k}$ so $\widetilde{y}_{k}>\widetilde{y}_{l}$ for $k<l$.

Assuming cost linearity, expression (5) boils down to

$$
\beta \frac{K-1}{K} \frac{e^{-\gamma_{k} x_{i k}}}{\sum_{j=1}^{n_{k}} e^{-\gamma_{k} x_{j k}}} y_{k}=1 \quad \text { for all } k \in \mathbb{K}
$$

Note that the left hand side in this expression is decreasing in $x_{i k}$ there cannot exist a generic equilibrium in which the above holds for some members and $\frac{\partial u_{i k}}{\partial x_{i k}}<0$ for the rest. The only two remaining porssibilities are that $i) \frac{\partial u_{i k}}{\partial x_{i k}}<0$ for all members; or $\left.i i\right) \frac{\partial u_{i k}}{\partial x_{i k}} \geq 0$ for all members and $p_{k}=1$.

It will be very convenient for us to denote the threshold.

$$
z \equiv \frac{1}{\beta} \frac{K}{K-1} .
$$

It is clear to see that the type $i$ ) of equilibrium within a group can only occur if $\widetilde{y}_{k}<z$. This activity threshold is decreasing in the effectiveness of effort $\beta$ and in the number of groups $K$. Hence, a group is more likely to be above it the more effective effort is and the higher the number of rival groups. On the other hand, the type $i i$ ) of equilibrium necessarily involves that at most one group can be active. The following Proposition characterizes existence of such equilibria.

Proposition 1 Assume valuations of victory are homogeneous within groups. If $\widetilde{y}_{1}<z$ no group is active in equilibrium. Otherwise, a pure strategy equilibrium exists if and only if $\widetilde{y}_{2}<z$. In that case, only group 1 is active, multiple equilibria exist and any equilibrium effort profile $\mathbf{x}_{1}^{*}$ satisfies $h_{1}\left(\mathbf{x}_{\mathbf{1}}^{*}\right)=1$ so $p_{1}\left(\mathbf{x}^{*}\right)=1$. 
Proof. For the first statement note that

$$
1>\frac{\widetilde{y}_{k}}{z}=\beta \frac{K-1}{K} \frac{y_{k}}{n_{k}}>\beta \frac{K-1}{K} \frac{e^{-\gamma_{k} x_{i k}}}{n_{k}-1+e^{-\gamma_{k} x_{i k}}} y_{k},
$$

so no member would like to deviate and become active. When $\widetilde{y}_{1}<z$ this applies to all groups. This is the unique equilibrium in this case because there no member could enjoy a higher marginal benefit of effort by becoming active. Now consider an equilibrium where some or all members in at least one group are active. It must then be of the type $i i$ ). For that it must be that $e^{-\gamma_{k} x_{i k}} / \sum_{j=1}^{n_{k}} e^{-\gamma_{k} x_{j k}}>\frac{1}{n_{k}}$ for all active members and that $p_{k}=1$. Otherwise, all members, including the inactive ones, would like to increase their effort. If this is the case for more than one group, this cannot constitute a pure-strategy equilibrium. Hence, it must be that all groups except group 1 remain inactive, i.e. $y_{2}<z$, and group 1 wins the contest for certain. For this to be the case

$$
h_{1}\left(\mathbf{x}_{1}^{*}\right)=\ln \left(\frac{1}{n_{1}} \sum_{j=1}^{n_{1}} e^{-\gamma_{1} x_{j 1}^{*}}\right)^{-\frac{\beta}{\gamma_{1}}}=1 \Leftrightarrow \sum_{j=1}^{n_{1}} e^{-\gamma_{1} x_{j 1}^{*}}=n_{1} e^{-\frac{\gamma_{1}}{\beta}}
$$

This can be attained through multiple strategy profiles, including some in which a number of members remain inactive. In any case, it must be that for the active members

$$
\frac{e^{-\gamma_{1} x_{i 1}}}{\sum_{j=1}^{n_{1}} e^{-\gamma_{1} x_{j 1}}} \frac{y_{1}}{z} \geq 1
$$

Not that $\widetilde{y}_{1}>z$ implies that one of these profiles is the one where all members make the same effort $x_{1}^{*}=\frac{1}{\beta n_{1}}$.

This result extends the one in Baik (1998) and Che and Gale (2000) to the case of homogeneous groups: In difference-form contests with linear costs, at most one contender is active. For this result to hold, linear effort is critical. Because it is constant, groups with a sufficiently high valuation of victory would like to contribute as much effort as possible. Hence, the lack of pure strategy equilibria. Only when there is one such a group an equilibrium in pure strategies can emerge. Even in that case, the assumption of constant marginal cost induces a multiplicity of equilibria where members contribute different amounts of effort but victory is in any case guaranteed.

3.2 Strictly convex cost: Despite its prevalence in contest theory, linear costs might not describe best the cost of effort in confrontations. When 
effort is time or money that must be raised in imperfectly competitive markets, its cost is very likely to be convex. In sport contests, fatigue makes effort increasingly costly; Brow and Minor (2011) show that this is the case in professional tennis. Moreover, the predictions derived from linear cost models can be rather non-robust. Esteban and Ray (2001) showed that the well-known "Olson paradox" is the result of a rather particular set of assumptions. It does not hold when the cost of collective action becomes convex enough. Next we will see that this is also the case in difference-form contests. The one-sidedness result so emphasized in the contest literature no longer holds when the marginal cost of effort is strictly increasing.

To obtain that result, it is important to note first that for any two active members $i$ and $j$ for who (5) holds it must be that $x_{i k}^{*}=x_{j k}^{*}$. Hence, if at least one member equilibrium effort is an interior optimum that must be so for all other members. This implies that a necessary condition for a group to be active in equilibrium is $\widetilde{y}_{k}>z$. Let us now define the following censored group income distribution as $\widetilde{\mathbf{y}}^{*}$, whose elements are defined as:

$$
\widetilde{y}_{k}^{*}=\max \left\{z, \widetilde{y}_{k}\right\} \text {. }
$$

Let us denote by $\widetilde{G}^{*}$ the geometric mean of the censored group incomes, i.e. $\widetilde{G}^{*}=\left(\prod_{l=1}^{K} \widetilde{y}_{l}^{*}\right)^{\frac{1}{K}}$. The following Proposition characterizes the equilibrium and the equilibrium winning probabilities in this contest.

Proposition 2 Assume homogenous valuations of victory within groups and strictly convex cost of effort. If $y_{1}^{*}>e^{z \phi} G^{*}$ only group 1 is active in equilibrium. Otherwise, group $k$ is active in equilibrium if and only if

$$
\widetilde{y}_{k}^{*}>\max \left\{z, e^{-\frac{\phi}{\beta K}} \widetilde{G}^{*}\right\}
$$

In that case, the equilibrium winning probabilities are equal to:

$$
p_{k}^{*}=\max \left\{0, \frac{1}{K}+\frac{\beta}{\phi} \ln \frac{\widetilde{y}_{k}^{*}}{\widetilde{G}^{*}}\right\} .
$$

Proof. For an active group, the equilibrium individual effort must be equal to

$$
x_{k}^{*}=\frac{1}{\phi} \ln \frac{\widetilde{y}_{k}}{z} .
$$

For this to constitute an equilibrium it must be that $\widetilde{y}_{k} z>1$, that is, the familiar $\widetilde{y}_{k}>z$. For the groups for which (5) holds, their impact boils 
down to $h_{k}\left(\mathbf{x}_{k}\right)=\frac{\beta}{\phi} \ln \frac{\widetilde{y}_{k}}{z}$. For an inactive group note that its impact can be written as $h_{k}\left(\mathbf{x}_{k}\right)=\frac{\beta}{\phi} \ln \frac{\widetilde{y}_{k}^{*}}{z}=0$. Then

$$
\begin{aligned}
p_{k}^{*} & =\frac{1}{K}+\frac{\beta}{\phi} \ln \frac{\widetilde{y}_{k}^{*}}{z}-\frac{1}{K} \frac{\beta}{\phi} \sum_{l=1}^{K} \ln \left(\frac{\widetilde{y}_{l}^{*}}{z}\right) \\
& =\frac{1}{K}+\frac{\beta}{\phi} \ln \frac{\widetilde{y}_{k}^{*}}{z}-\frac{1}{K} \frac{\beta}{\phi} \ln \left(\prod_{l=1}^{K} \frac{\widetilde{y}_{l}^{*}}{z}\right) \\
& =\frac{1}{K}+\frac{\beta}{\phi}\left[\ln \frac{\widetilde{y}_{k}^{*}}{z}+\ln \frac{z}{\left(\prod_{l=1}^{K} \widetilde{y}_{l}^{*}\right)^{\frac{1}{K}}}\right],
\end{aligned}
$$

which is the expression stated in the text of the Proposition. For that probability to be positive for an active group it must be that $p_{k}^{*}>0$, which requires $\widetilde{y}_{k}^{*}>e^{-\frac{\phi}{\beta K}} G^{*}$. This together with the condition $\widetilde{y}_{k}>z$ implies condition (7). On the other hand, simple calculations show that $p_{1}^{*}<1$ if and only if $\widetilde{y}_{1}^{*}<e^{z \phi} \widetilde{G}^{*}$. Otherwise, group 1 wins with probability one and no other group is active. This is because even by exerting optimal effort $x_{k}^{*}$ their probability of winning remains equal to zero. So $\widetilde{y}_{1}^{*}<e^{z \phi} G^{*}$ is a necessary condition for more than one group to be active in equilibrium.

It is important to observe the stark contrast between Propositions 1.1 and 1.2. In the former, at most one group is active in equilibrium whereas in the latter case, multiple active groups are possible. Moreover, equilibrium existence with linear cost is ensured only if the $\widetilde{y}_{2}$ is sufficiently low, whereas with strictly convex cost, a sufficiently high $\widetilde{y}_{2}$ ensures that at least two groups are active in equilibrium. Still, it remains true that a group valuation of victory must be high enough for it to be active. This is due to the fact that under the difference-form CSF a group can prevail even if it remains inactive. This should be seen as a realistic outcome. Not all groups in society engage in confrontation nor all employees in organisations engage in influence activities. Only those with a sufficiently intense preference for victory.

\section{Heterogeneous groups}

Let us now consider the case of heterogenous groups. From now, we will be interested in the following two questions. First, how the level of heterogeneity or inequality affects the winning probability of a group. Secondly, 
we will be interested in whether groups would be interested in engaging in self-enforcing redistribution in order to enhance their chances of prevailing in the contest. In this section, we characterize the equilibria of the contest when valuations are heterogeneous and show that they display a number of appealing features. In the following section, we answer the two questions just mentioned.

First, when measuring heterogeneity within groups we will make extensive use of generalized means (Hardy et al, 1934). These are defined as

$$
\bar{y}_{r_{k}}=\left[\frac{1}{n_{k}} \sum_{j=1}^{n_{k}} y_{j k}^{r_{k}}\right]^{\frac{1}{r_{k}}} \quad \text { for } r_{k} \in \mathbb{R}, r_{k} \neq 0,
$$

and as the geometric mean for $r_{k}=0$. The case $r_{k}=1$ corresponds to the arithmetic mean and $r_{k}=-1$ to the harmonic mean. Moreover, for any given vector, $\bar{y}_{r_{k}}$ is increasing in $r_{k}$.

Now, let us turn our attention to the FOC of this problem. Let us order members in decreasing order so $y_{i k}>y_{j k}$ for $i<j$. Because members differ in income, it might be the case that some members remain inactive in equilibrium. If this is the case, because the marginal benefit of effort is decreasing, it must be that if $x_{i k}^{*}=0$ and $x_{j k}^{*}>0$ then $y_{j k}>y_{i k}$. Then, expression (5) becomes:

$$
\frac{\partial u_{i k}}{\partial x_{i k}}=\frac{e^{-\gamma_{k} x_{i k}}}{n_{k}-n_{k}^{*}+\sum_{j=1}^{n_{k}^{*}} e^{-\gamma_{k} x_{j k}}} \frac{y_{i k}}{z}-e^{\phi x_{i k}}=0,
$$

where $n_{k}^{*}$ is the number of active members. Unfortunately, this expression renders impossible to solve the system of FOCs beyond some particular cases. Still, there a relevant particular cases where closed form solutions are possible.

4.1 All groups fully (in)active: We will refer to a group whose all members are active (inactive) as a fully active (inactive) group. Let us now characterize the conditions under which all groups are either active or inactive in equilibrium. Note that for any two members $i$ and $j$, their optimal effort choices satisfy

$$
\frac{e^{x_{i k}}}{e^{x_{j k}}}=\left(\frac{y_{i k}}{y_{j k}}\right)^{\frac{1}{\phi+\gamma_{k}}}
$$

This implies that members' optimal efforts become more similar as efforts become more complementary or the cost function more convex. Adding up 
the FOCs for all members yields

$$
\sum_{j=1}^{n_{k}} e^{-\gamma_{k} x_{j k}}=\left(\sum_{j=1}^{n_{k}} y_{j k}^{\frac{-\gamma_{k}}{\phi+\gamma_{k}}}\right)^{\frac{\phi+\gamma_{k}}{\phi}} z^{\frac{\gamma_{k}}{\phi}}
$$

which we then plug back in (5) to obtain

$$
x_{i k}^{*}=\ln \left[\frac{y_{i k}}{z}\right]^{\frac{1}{\phi+\gamma_{k}}}-\frac{1}{\phi} \ln \left[\sum_{j=1}^{n_{k}}\left(\frac{y_{i k}}{z}\right)^{\frac{-\gamma_{k}}{\phi+\gamma_{k}}}\right],
$$

A necessary condition for this equilibrium to exist is then that the cost of effort must be strictly convex, i.e. $\phi>0$. Now denote $r_{k}=-\frac{\gamma_{k}}{\phi+\gamma_{k}} \in(-1,0]$ and by $\bar{y}_{r_{k}}$ the mean income of order $r_{k}$ as in (8). Similarly to above, it will be useful from now on to employ the vector of censored group incomes $\overline{\mathbf{y}}^{*}$ whose elements are given by

$$
\bar{y}_{k}^{*}=\max \left\{\frac{\bar{y}_{r_{k}}}{n_{k}}, z\right\} .
$$

Again, and without loss of generality, let us index groups in a decreasing manner according to $\bar{y}_{k}^{*}$ and denote by $G_{r}^{*}$ the geometric mean of censored groups incomes in $\overline{\mathbf{y}}^{*}$, i.e. $G_{r}^{*}=\left(\prod_{l=1}^{K} \bar{y}_{l}^{*}\right)^{\frac{1}{K}}$. The following Proposition characterizes under which condition this type of equilibrium exists and the winning probabilities under it.

Proposition 3 Assume $y_{r_{1}}^{*}<e^{z \phi} G_{r}^{*}$. Then for each group $k$ there exists an income threshold

$$
\widehat{y}_{k} \equiv n_{k} z\left[\frac{\bar{y}_{r_{k}}}{n_{k} z}\right]^{\frac{r_{k}}{1+r_{k}}}
$$

such that an equilibrium in which all groups are either fully active or fully inactive exists if and only if for at least one group $y_{n_{k} k}>\widehat{y}_{k}$ and $y_{1 k}<\widehat{y}_{k}$ for the rest of groups. In that case, equilibrium winning probabilities are equal to

$$
p_{k}^{*}=\max \left\{0, \frac{1}{K}+\frac{\beta}{\phi} \ln \frac{\bar{y}_{r_{k}}^{*}}{G_{r}^{*}}\right\} .
$$

Proof. First of all, note that for a member to be active in equilibrium it must be that $x_{i k}^{*}>0$ so

$$
\frac{y_{i k}}{z}>\left[\sum_{j=1}^{n_{k}}\left(\frac{y_{j k}}{z}\right)^{\frac{-\gamma_{k}}{\phi+\gamma_{k}}}\right]^{\frac{\phi+\gamma_{k}}{\phi}} \Leftrightarrow \frac{y_{i k}}{n_{k} z}>\left[\frac{1}{n_{k}} \sum_{j=1}^{n_{k}}\left(\frac{y_{j k}}{n_{k} z}\right)^{r_{k}}\right]^{\frac{1}{1+r_{k}}} \Leftrightarrow y_{i k}>\widehat{y}_{k} .
$$


For this to hold for all members, it must hold for member $n_{k}$. Because $y_{n_{k} k} \leq \bar{y}_{r_{k}}$, the fact that $\frac{y_{n_{k} k}}{n_{k} z}>\left[\frac{\bar{y}_{r_{k}}}{n_{k} z}\right]^{\frac{r_{k}}{1+r_{k}}}$ implies that $\frac{\bar{y}_{r_{k}}}{n_{k} z}>1$, or in other words that $\bar{y}_{k}^{*}=\frac{\bar{y}_{r_{k}}}{n_{k}}$. On the other hand, if it does not hold for member 1 of the group, that group will be fully inactive. By the same token, it must be that $\frac{\bar{y}_{r_{k}}}{n_{k} z}<1$ so $\bar{y}_{k}^{*}=z$. So we can write a group impact simply as

$$
h_{k}\left(\mathbf{x}_{k}^{*}\right)=\frac{\beta}{\phi} \ln \frac{y_{r_{k}}^{*}}{z} .
$$

Plugging the resulting impact into (1) yields the following winning probability for an active group.

$$
\begin{aligned}
p_{k}^{*} & =\frac{1}{K}+\frac{\beta}{\phi} \ln \frac{\bar{y}_{r_{k}}^{*}}{z}-\frac{1}{K} \sum_{l=1}^{K} \frac{\beta}{\phi} \ln \frac{\bar{y}_{r_{l}}^{*}}{z} \\
& =\frac{1}{K}+\frac{\beta}{\phi} \ln \frac{\frac{\bar{y}_{r_{l}}^{*}}{z}}{\left(\prod_{l=1}^{K} \frac{\bar{y}_{r_{l}}^{*}}{z}\right)^{\frac{1}{K}}},
\end{aligned}
$$

which is the expression stated in the text of the Proposition. It is easy to obtain then that for group $1, p_{1}^{*}<1$ if and only if $\bar{y}_{1}^{*}<e^{\phi z} G_{r}^{*}$.

This Proposition shows that success of a group in the contest is related to the relationship between its mean income group and the average of all mean group incomes. Note that because $r_{k}=-\frac{\gamma_{k}}{\phi+\gamma_{k}}$ is decreasing in $\gamma_{k}$, the impact of the group decreases as efforts become more complementary. This is because complementarity makes the effort of the low valuation members more critical. These are the members with the lowest incentive to contribute so as the group becomes more dependent on them its chances of prevailing become smaller.

A common criticism of difference-form CSFs is that they are not scale independent, that is, they are not homogeneous of degree zero. Changing the unit of measurement of effort from soldiers to battalions or from dollars to euros, changes the relative success of contenders (Alcalde and Dahm, 2007; Corchon, 2007; Bevia and Corchon, 2012). Although the differenceform CSF we employ is indeed not homogeneous of degree zero, inspection of (10) shows that measurement units do not matter locally in equilibrium.

Corollary 4 (Group scale invariance) Consider an equiproportional change on all group valuations such that no inactive group becomes active nor viceversa. Then equilibrium winning probabilities remain unchanged. 
Recall that generalized means are homogeneous of degree one, i.e. $\bar{y}_{r_{k}}\left(\varepsilon \mathbf{y}_{k}\right)$ $=\varepsilon \bar{y}_{r_{k}}\left(\mathbf{y}_{k}\right)$ for $\varepsilon>0$. Hence, for local homogeneity of degree zero to hold it must be that $\varepsilon \cdot \bar{y}_{r_{K^{*}+1}}^{*}<z$, where $K^{*}+1$ is the fully inactive group with the highest group mean income. Hence, our difference-form group contests suffer less severely from the problem of scale dependence, at least in equilibrium, that plague other difference-form contests.

4.2 Linear impact: The case $\gamma_{k}=0$ for all $k$ corresponds to the case studied by Che and Gale (2000) and derived by Corchon and Dahm (2011) where the impact function is just linear. In that case,

$$
h_{k}\left(\mathbf{x}_{k}\right)=\frac{\beta}{n_{k}} \sum_{j=1}^{n_{k}} x_{j k}
$$

Note that because the CSF is separable and the marginal impact of effort is a constant $\frac{\beta}{n_{k}}$, any equilibrium must be in dominant strategies. is:

The FOC in (9) implies that the optimal effort choice of an active member

$$
x_{i k}^{*}=\frac{1}{\phi} \ln \frac{y_{i k}}{n_{k} z},
$$

so a member is active if and only if $y_{i k}>n_{k} z$. This determines the set of active members: It consists of the $n_{k}^{*}$ members whose valuations are above $n_{k} z$. As above define the vector of censored valuations $\mathbf{y}_{k}^{*}$ as the one whose elements are $y_{i k}^{*}=\max \left\{\frac{y_{i k}}{n_{k}}, z\right\}$. Finally denote as $k^{*}=\arg \max \left\{G_{k}^{*}\right\}$ where $G_{k}^{*}$ is the geometric group mean of the censored valuations.

Proposition 5 Assume $G_{k^{*}}^{*}<e^{\phi z} G^{*}$ where $G^{*}=\left(\prod_{l=1}^{K} G_{l}^{*}\right)^{\frac{1}{K}}$. Then in equilibrium the group winning probabilities are given by

$$
p_{k}^{*}=\max \left\{0, \frac{1}{K}+\frac{\beta}{\phi} \ln \frac{G_{k}^{*}}{G^{*}}\right\} .
$$

Proof. Plugging the optimal choice in the impact function yields:

$$
h_{k}\left(\mathbf{x}_{k}^{*}\right)=\frac{\beta}{\phi n_{k}} \sum_{i=1}^{n_{k}} \ln \frac{y_{i k}^{*}}{z}=\frac{\beta}{\phi}\left\{\ln \left(\prod_{j=1}^{n_{k}} y_{j k}^{*}\right)^{\frac{1}{n_{k}}}-\ln z\right\}=\frac{\beta}{\phi}\left\{\ln G_{k}^{*}-\ln z\right\} .
$$


So winning probabilities become.

$$
\begin{aligned}
p_{k}^{*} & =\frac{1}{K}+\frac{\beta}{\phi}\left\{\ln G_{k}^{*}-\ln z\right\}-\frac{1}{K} \frac{\beta}{\phi} \sum_{l=1}^{K}\left\{\ln G_{l}^{*}-\ln z\right\} \\
& =\frac{1}{K}+\frac{\beta}{\phi}\left\{\ln G_{k}^{*}-\frac{1}{K} \sum_{l=1}^{K} \ln G_{l}^{*}\right\}=\frac{1}{K}+\frac{\beta}{\phi} \ln \frac{G_{k}^{*}}{\left(\prod_{l=1}^{K} G_{l}^{*}\right)^{\frac{1}{K}}} .
\end{aligned}
$$

For this probability to be smaller than 1 it must be that for $k^{*}=$ $\arg \max \left\{G_{k}^{*}\right\}$ it holds that $G_{k^{*}}^{*}<e^{\phi z} G^{*}$.

By simplifying on the technological side, this case illustrates perfectly well that the relative success of the group depends on the relative position of its mean valuation with respect to the mean of the mean group valuations. In the particular case of linear impact functions, these means are geometric means. Groups with more active members, that is, with more members whose valuation is above the activity threshold $n_{k} z$ are more successful in the contest. Moreover, changes in valuations which imply that no additional member jumps above the threshold have no impact on the success of the group. It can be seen then that local scale invariance also holds as well in this case:

Corollary 6 (Member scale invariance) Consider an equiproportional change on all valuations such that no member no inactive group become active nor viceversa. Then equilibrium winning probabilities remain unchanged.

The requirements for local invariance in measurement units to hold are stronger than before. Now it must be the case that $\varepsilon>0$ is such that $\varepsilon<\min \left\{\frac{n_{k} z}{y_{n_{k}^{*}+1 k}}\right\}_{k=1}^{K}$, where recall that $n_{k}^{*}+1$ is the inactive member with the highest valuation.

4.3 Linear costs: As we saw in the previous Section, the assumption of linear costs can lead to non-robust predictions. However, as we will see, under heterogeneity in individual valuations of victory this problem is ameliorated. More importantly, the linearity assumption allows us to derive closed form solutions when groups are not fully active in equilibrium. 
Taking expression (9) and adding it up for all active members yields:

$$
\sum_{j=1}^{n_{k}^{*}} e^{-\gamma_{k} x_{i k}}=\frac{n_{k}-n_{k}^{*}}{\frac{H_{k}^{*}}{z n_{k}^{*}}-1}
$$

where $H_{k}^{*}=\frac{n_{k}^{*}}{\sum_{j=1}^{n_{k}^{*}} \frac{1}{y_{i k}}}$ is the harmonic mean of the individual valuations of the active members in group $k$.

Combining this with the expression (9) one obtains that

$$
x_{i k}^{*}=\ln \left[y_{i k} \frac{\frac{H_{k}^{*}}{z n_{k}^{*}}-1}{\left(n_{k}-n_{k}^{*}\right) \frac{H_{k}^{*}}{n_{k}^{*}}}\right]^{\frac{1}{\gamma_{k}}} \Leftrightarrow y_{i k}>\frac{n_{k}-n_{k}^{*}}{\frac{1}{z}-\frac{n_{k}^{*}}{H_{k}^{*}}}
$$

So the set of active members is given by all members for who the above holds. These must be the $n_{k}^{*}$ members with the highest valuation since recall that if $x_{i k}^{*}=0$ and $x_{j k}^{*}>0$ then $y_{j k}>y_{i k}$. So for a group to have at least one active member $y_{1 k}>n_{k}^{*} z$. On the other hand, if for at least two groups all their members want to be active, we go back to the non-existence result in Proposition 1.2. For this not to be the case it is needed that in all groups at least one agent must want to remain inactive so

$$
y_{n_{k} k}<\frac{1}{\frac{1}{z}-\sum_{j=1}^{n_{k}-1} y_{j k}} .
$$

if this condition does not hold for at least two groups, these groups would want to be fully active and we go back to the non-existence result in Proposition 1.1. Let us assume that this condition is satisfied. Before that it will be useful to define $u_{k}=\frac{n_{k}-n_{k}^{*}}{n_{k}}$ as the inactivity rate of group $k$ and as $a_{k}=1-\frac{z n_{k}^{*}}{H_{k}^{*}}$ the activity gap of group $k$. The inactivity rate is the proportion of members in $k$ who remain inactive. The activity gap measures by how much the harmonic mean of valuations for active members is above the activity threshold $z n_{k}^{*}$.

Proposition 7 Under linear costs, assuming that $\gamma_{k}=\gamma$ for all $k$ and that (13) holds for all groups there exists an equilibrium where $n_{k}^{*}<n_{k}$ members are active in each group and under which winning probabilities are equal to

$$
p_{k}^{*}=\frac{1}{K}+\frac{\beta}{\gamma} \ln \frac{a_{k}}{G_{a}}-\frac{\beta}{\gamma} \ln \frac{u_{k}}{G_{u}},
$$

where $G_{a}$ and $G_{u}$ are the geometric mean of the inactivity rates and the activity gaps respectively. 
Proof. Using (12) to compute the impact of a group yields:

$$
\begin{aligned}
h_{k}\left(\mathbf{x}_{k}^{*}\right) & =\ln \left[\frac{1}{n_{k}}\left(n_{k}-n_{k}^{*}+\sum_{j=1}^{n_{k}^{*}} e^{-\gamma_{k} x_{i k}}\right)\right]^{-\frac{\beta}{\gamma_{k}}}=-\frac{\beta}{\gamma_{k}} \ln \left[\frac{n_{k}-n_{k}^{*}}{n_{k}} \frac{\frac{H_{k}^{*}}{z n_{k}^{*}}}{\frac{H_{k}^{*}}{z n_{k}^{*}}-1}\right] \\
& =\frac{\beta}{\gamma_{k}} \ln \left[\frac{1-\frac{z n_{k}^{*}}{H_{k}^{*}}}{1-\frac{n_{k}^{*}}{n_{k}}}\right]=\frac{\beta}{\gamma_{k}} \ln \frac{a_{k}}{u_{k}}
\end{aligned}
$$

Note that for a fully inactive group, i.e. $n_{k}^{*}=0$, its impact is $h_{k}\left(\mathbf{x}_{k}\right)=0$. The winning probabilities then become

$p_{k}^{*}=\frac{1}{K}+\beta \ln \left[\frac{a_{k}}{u_{k}}\right]^{\frac{1}{\gamma_{k}}}-\frac{\beta}{K} \sum_{l=1}^{K} \ln \left[\frac{a_{l}}{u_{l}}\right]^{\frac{1}{\gamma_{l}}}=\frac{1}{K}+\beta \ln \frac{a_{k}^{\frac{1}{\gamma_{k}}}}{\left[\prod_{l=1}^{K} a_{l}^{\frac{1}{\gamma_{l}}}\right]^{\frac{1}{K}}}-\beta \ln \frac{u_{k}^{\frac{1}{\gamma_{k}}}}{\left[\prod_{l=1}^{K} u_{l}^{\frac{1}{\gamma_{l}}}\right]^{\frac{1}{K}}}$,

which yields the expression stated in the text of the Proposition under the assumption that $\gamma_{k}=\gamma$ for all $k$.

Although the analysis of the contest becomes quite intrincate at this point, this result shows that it is still possible to derive predictions on the relative success of groups. Groups with higher activity gaps and lower inactivity rates should have higher chances of prevailing. Both are not independent but it is possible to see that for two groups with the same activity gap, the one with the lower inactivity rate should be more likely to attain victory. Similarly, for two groups with the same number of active members, the more likely to prevail should be the one with the highest harmonic mean $H_{k}^{*}$ and the highest size $n_{k}$.

\section{Inequality and redistribution}

We are finally in the position to answer our two previous questions: First, whether inequality helps or hinders groups in difference-form contests. And second, to what extent redistribution can help them to enhance their chances of prevailing. In order to tackle this second question we must thus assume that these valuations represent the income that members must defend from outsiders or the claims they have over the object being contested. In that case, it is meaningful to talk about redistribution.

The standard concept to use when dealing with inequality is the PigouDalton Principle: It is a well-known and widely-employed criterion used to rank distributions by their level of inequality. 
Definition 8 (Pigou-Dalton transfer principle) Take two vectors $\mathbf{y}_{k}$ and $\mathbf{y}_{k}^{\prime}$, where $\mathbf{y}_{k}^{\prime}$ is obtained by adding $\Delta>0$ to $y_{i k}$ and substracting it from $y_{j k}$ where $y_{i k}<y_{j k}$ and such that $y_{i k}-\Delta<y_{j k}-\Delta$. Then the distribution $\mathbf{y}_{k}^{\prime}$ is less unequal than $\mathbf{y}_{k}$.

This principle states that a rank-preserving progressive transfer cannot increase inequality. Note that a progressive transfer makes the original distribution to be majorized by the new one. Because means of order $r$ are Schur-concave when $r \leq 1$, a Pigou-Dalton transfer increases $\bar{y}_{r}$ for all. That is why means of order $r$ are commonly employed in the inequality measurement literature. Note that this property applies to our context since for all groups $r_{k} \in(-1,0]$.

Proposition 9 (Redistribution) Consider contests with heterogeneous groups with linear impact functions or in which all groups are either fully active or fully inactive. Then, progressive transfers within a group weakly increase its equilibrium winning probability.

Proof. Consider first the case in subsection 5.1. There winning probabilities are given by (10). Note that the ratio $\frac{\bar{y}_{r_{k}}^{*}}{G_{r}^{*}}$ is increasing in $\bar{y}_{r_{k}}^{*}$. Then, since a progressive transfer weakly increases $\bar{y}_{r_{k}}^{*}$, the winning probability $p_{k}^{*}$ weakly increases as a result. Now consider the case in subsection 5.2. There winning probabilities are given by expression (11). Note that $G_{k}^{*}$ is just the mean of order -1 of the individual valuations. A progressive transfer makes it increase. Because the ratio $\frac{G_{k}^{*}}{G^{*}}$ is increasing in $G_{k}^{*}$, the same as above applies.

This result shows that in difference-form group contests, members may benefit from engaging in income redistribution. Reducing the dispersion in valuations makes the group relatively more successful. Part of this result is driven by the convexity of the cost function. High valuations members do not exert very high effort since its marginal cost increase quite quickly. A transfer given to a low valuation member induces a higher increase in effort than if it is received by a high valuation member. This is because the marginal cost of effort is lower for the low valuation member since she was exerting a lower effort than the high valuation one.

Finally, we would like to address the issue of relative success. We would like to check whether more egalitarian groups are more likely to prevail. In order to perform such comparisons, let us use the Atkinson index of 
inequality (Atkinson,1970) which is defined as

$$
I_{\zeta}\left(\mathbf{y}_{k}\right)=1-\frac{\bar{y}_{\zeta}}{\mu_{k}},
$$

where $\mu_{k}$ is average valuation in group $k$ and $\bar{y}_{\zeta}$ is just the mean of order $1-\xi$ of the valuations. In Atkinson's formulation, the parameter $\xi \geq 0$ is normative and measures the inequality aversion of the evaluator. It is equal to zero when $\zeta=0$, i.e. $\bar{y}_{k}=\mu_{k}$, and equal to the ratio $\frac{\bar{y}_{k}-y_{n_{k}}}{\bar{y}_{k}}$ when $\zeta \rightarrow \infty$. The Atkinson index can be used to compare distributions across societies with different sizes and per capita incomes. Among its properties, the index is normalized to be between zero and one, it satisfies the PigouDalton principle and it is consistent with the Lorenz dominance ordering.

Let us now use this index to state the following result. Before that, we need to homogenize the inequality aversion parameter across groups. Hence assume that $\gamma_{k}$ is identical across groups and denote $\zeta^{*}=1-\frac{\gamma}{\gamma+\phi}$. Then, denote by $\mu_{k}^{*}$ the average censored valuation in group $k$.

Proposition 10 (Inequality and success) Consider contests with heterogeneous groups with linear impact functions or in which all groups are either fully active or fully inactive. Then, if $I_{\zeta^{*}}\left(\mathbf{y}_{k}^{*}\right)<I_{\zeta^{*}}\left(\mathbf{y}_{l}^{*}\right)$ and $\mu_{k}^{*} \geq \mu_{l}^{*}$, the equilibrium winning probability of group $k$ is higher than for group $l$.

Proof. Rewritting the Atkinson index yields

$$
\bar{y}_{\substack{\zeta^{*} \\ k}}=\bar{y}_{k}\left(1-I_{\zeta^{*}}\left(\mathbf{y}_{k}\right)\right)=\frac{Y}{n_{k}}\left(1-I_{\zeta^{*}}\left(\mathbf{y}_{k}\right)\right)
$$

where the last equality comes from our assumption that $\sum_{i=1}^{n_{k}} y_{i k}=Y$ for all $k$. As a matter of fact, this is the expression for the Atkinson-Kolm-Sen social welfare function (Sen, 1973). Hence, under the conditions stated in the Proposition, it is clear that $\bar{y}_{\zeta^{*}}>\bar{y}_{\zeta^{*}}$.

By looking at (10) and (11) it is straightforward to see that group $k$ enjoys a higher probability of success than group $l$ if and only if $\bar{y}_{k}^{*}>\bar{y}_{l}^{*}$ and $G_{k}^{*}>G_{l}^{*}$ in each respective case. These are comparisons between means of order order $1-\zeta^{*}=-\frac{\gamma}{\phi+\gamma}$, where in the latter case it is assumed that $\gamma=0$. Hence, the ranking $\bar{y}_{\zeta^{*}}>\bar{y}_{\zeta^{*}}$ applies to them and allows us to conclude that $p_{k}^{*}>p_{l}^{*}$.

This result shows that given two groups of the same size, the more egalitarian group according to the Atkinson index is more likely to prevail in 
the contest. Because the index is consistent with the Lorenz criterion, the Proposition contemplates as a particular case scenarios where the distribution in of the groups Lorenz dominates the other. Let us emphasize that inequality is measured over the distribution of censored valuations. Hence, the index is the same for two groups with very different distribution of valuations below the activity threshold but identical in every other respect. The conclusion is that there exists strong forces in favor of egalitarianism in difference-form group contests. But this egalitarianism must apply to the set of active members, which are the ones with higher valuations.

\section{Conclusion}

In this paper we have offered the first systematic study of group contests where groups' winning probabilities depend on the difference between their effective efforts. These difference-form group contests are well suited to described a wide variety of situations where a set of groups compete for an object or award. These include military combat, union-firm conflicts, influence activities within organization and political lobbying within federal countries.

Our first result is that the non-existence of pure strategy equilibria and the ensuing monopolization highlighted in the previous literature rest critically on the assumption of linear cost. This was to be expected. This lack of robustness of the predictions under linear costs has been shown to apply as well in other contests. Still, some groups can remain inactive in equilibrium when costs are strictly convex. This is because the difference-form CSF can award a positive winning probability to inactive contenders. We see this result as a realistic one. In many real instances contenders remain inactive: Not all countries engage in warfare; neither all employees engage in influence activities.

The case of heterogeneous members extends this pattern inside groups. Members with low enough valuations remain inactive in equilibrium. Again, this seems to us a very realistic feature. We show in this case that inequality in mebers' valuations of victory is bad for a group. Unequal groups are less likely to win the contest. It is important to reiterate that what matters there is inequality within the set of active members. Not all types of redistribution within groups can enhance its chances of prevailing. Only progressive transfers which make the active group more egalitarian or which induce some inactive members to become active can lead the group to a more likely victory. 


\section{References}

[1] Alcalde, J. and Dahm, M. 2007. Tullock and Hirshleifer: a meeting of the minds. Review of Economic Design, 11(2), 101-124.

[2] Anderton, C. H. 2000. An insecure economy under ratio and logistic conflict technologies. Journal of Conflict Resolution, 44(6), 823-838.

[3] Atkinson, A. B. 1970. On the measurement of inequality. Journal of Economic Theory, 2, 244-263.

[4] Baik, K. H. 1993. Effort Levels in Contests: The Public-Good Prize Case. Economics Letters, 41, 363-67.

[5] Baik, K. H. 1998. Difference-form contest success functions and effort levels in contests. European Journal of Political Economy 14(4), 685701.

[6] Bevia, C. and Corchon, L. 2012. Relative Difference Contest Success Functions. Working Paper, SSRN-id2017279.

[7] Blackorby, C. and Donaldson, D. 1980. A theoretical treatment of indices of absolute inequality. International Economic Review, 21, 107136.

[8] Brown, J. and Minor, D. B. (2011). Selecting the Best? Spillover and Shadows in Elimination Tournaments. NBER Working Paper No. 17639 .

[9] Che, Y.-K. and Gale I. 2000. Difference-Form Contests and the Robustness of All-Pay Auctions. Games and Economic Behavior 30, 22-43.

[10] Corchón, L. 2007. The theory of contests: a survey. Review of Economic Design, 11, 69-100.

[11] Corchón, L. and Dahm, M. 2010. Foundations for contest success functions. Economic Theory, 43(1), 81-98.

[12] Corchón, L. and Dahm, M. 2011. Welfare Maximizing Contest Success Functions when the Planner Cannot Commit. Journal of Mathematical Economics, 47(3), 309-317.

[13] Cubel, M. and Sanchez-Pages, S. 2013. Inequality in Conflicts. Mimeo. 
[14] Esteban, J. and Ray, D. 2001. Collective action and the group size paradox. American Political Science Review, 95(3), 663-672.

[15] Esteban, J. and Ray, D. 2011. A Model of Ethnic Conflict. Journal of the European Economic Association, 9(3):496-521.

[16] Finer, S. 1975. State and Nation Building in Europe: The Role of the Military, in The Formation of National States in Western Europe, Charles Tilly, ed. Princeton University Press: Princeton.

[17] Gersbach, H. and Haller, H. 2009. The affectionate society: does competition for partners promote friendliness? Economic Theory, 40(3), 389-403.

[18] Hardy, G., Littlewood, J.L. and Pólya, G. 1934. Inequalities. Cambridge University Press: Cambridge.

[19] Hillman, A. and Riley, J. 1989. Politically contestable rents and transfers. Economics and Politics, 1, 17-39.

[20] Hirshleifer, J. 1983. From Weakest-Link to Best-Shot: The Voluntary Provision of Public Goods. Public Choice, 41, 371-86.

[21] Hirshleifer, J. 1989. Conflict and rent-seeking success functions: ratio vs. difference models of relative success. Public Choice, 63, 101-112.

[22] Hirshleifer, J. 1991. The technology of conflict as an economic activity. American Economic Review, 81(2), 130-134.

[23] Hirshleifer, J. 2000. The macrotechnology of conflict. Journal of Conflict Resolution, 44(6), 773-792.

[24] Jia, H. and Skaperdas, S. 2011. Technologies of Conflict. In: Garfinkel, M.R., Skaperdas, S., eds., Oxford Handbook of the Economics of Peace and Conflict. Oxford Press: Oxford.

[25] Jia, H., Skaperdas, S., and Vaidya, S. 2013. Contest functions: Theoretical foundations and issues in estimation. International Journal of Industrial Organization, 31(3), 211-222.

[26] Kolm, S.-C. 1976a. Unequal inequalities I. Journal of Economic Theory, $12,416-442$.

[27] Kolm, S.-C. 1976b. Unequal inequalities II. Journal of Economic Theory, 13, 82-111. 
[28] Kolmar, M. and Rommeswinkel, H. 2013. Technlogical Determinant of the Group-Size Paradox. Forthcoming Journal of Economic Behavior and Organization.

[29] Konrad, K.A., 2009. Strategy and Dynamics in Contests. Oxford University Press, New York.

[30] Lee, D. 2012. Weakest-link contests with group-specific public good prizes. European Journal of Political Economy, 28, 238-248.

[31] Milgrom, P. 1988. Employment contracts, influence activities, and efficient organization design. Journal of Political Economy, 96, 42-60.

[32] Münster, J. 2009. Group contest success functions. Economic Theory, $41(2), 345-357$.

[33] Münster, J. and Staal, K. 2011. War with Outsiders Makes Peace Inside. Conflict Management and Peace Science, 28(2), 91-110.

[34] Nitzan, S. 1991. Rent-Seeking with Non-identical Sharing Rules. Public Choice, 71(1-2), 43-50.

[35] Polishchuk, L. and Tonis, A. 2013. Endogenous contest success functions: a mechanism design approach. Economic Theory, 52(1), 271-297.

[36] Pollak, R. A. 1971. Additive Utility Functions and Linear Engel Curves. The Review of Economic Studies, 38(4), 401-414.

[37] Sen, A. K. 1973. On Economic Inequality. Oxford: Clarendon Press.

[38] Skaperdas, S. 1996. Contest success functions. Economic Theory, 7(2), 283-290.

[39] Skaperdas, S. and Syropoulos, C., 1996. Can the shadow of the future harm cooperation? Journal of Economic Behavior and Organization, $29(3), 355-372$.

[40] Skaperdas, S. and Vaidya, S., 2012. Persuasion as a contest. Economic Theory, 51, 465-486.

[41] Tullock, G. 1967. The welfare costs of tariffs, monopolies and theft. Western Economic Journal, 5, 224-232.

[42] Ueda, K. 2002. Oligopolization in collective rent-seeking. Social Choice and Welfare, 19(3), 613-626. 
[43] Wärneryd, K. 1998. Distributional Conflict and Jurisdictional Organization. Journal of Public Economics, 69, 435-450. 
2011/1, Oppedisano, V; Turati, G.: "What are the causes of educational inequalities and of their evolution over time in Europe? Evidence from PISA"

2011/2, Dahlberg, M; Edmark, K; Lundqvist, H.: "Ethnic diversity and preferences for redistribution "

2011/3, Canova, L.; Vaglio, A.: "Why do educated mothers matter? A model of parental help"

2011/4, Delgado, F.J.; Lago-Peñas, S.; Mayor, M.: "On the determinants of local tax rates: new evidence from Spain"

2011/5, Piolatto, A.; Schuett, F.: "A model of music piracy with popularity-dependent copying costs"

2011/6, Duch, N.; García-Estévez, J.; Parellada, M.: "Universities and regional economic growth in Spanish regions"

2011/7, Duch, N.; García-Estévez, J.: "Do universities affect firms' location decisions? Evidence from Spain"

2011/8, Dahlberg, M.; Mörk, E.: "Is there an election cycle in public employment? Separating time effects from election year effects"

2011/9, Costas-Pérez, E.; Solé-Ollé, A.; Sorribas-Navarro, P.: “Corruption scandals, press reporting, and accountability. Evidence from Spanish mayors"

2011/10, Choi, A.; Calero, J.; Escardíbul, J.O.: "Hell to touch the sky? private tutoring and academic achievement in Korea"

2011/11, Mira Godinho, M.; Cartaxo, R.: "University patenting, licensing and technology transfer: how organizational context and available resources determine performance"

2011/12, Duch-Brown, N.; García-Quevedo, J.; Montolio, D.: "The link between public support and private R\&D effort: What is the optimal subsidy?"

2011/13, Breuillé, M.L.; Duran-Vigneron, P.; Samson, A.L.: "To assemble to resemble? A study of tax disparities among French municipalities"

2011/14, McCann, P.; Ortega-Argilés, R.: "Smart specialisation, regional growth and applications to EU cohesion policy"

2011/15, Montolio, D.; Trillas, F.: "Regulatory federalism and industrial policy in broadband telecommunications"

2011/16, Pelegrín, A.; Bolancé, C.: "Offshoring and company characteristics: some evidence from the analysis of Spanish firm data"

2011/17, Lin, C.: "Give me your wired and your highly skilled: measuring the impact of immigration policy on employers and shareholders"

2011/18, Bianchini, L.; Revelli, F.: "Green polities: urban environmental performance and government popularity"

2011/19, López Real, J.: "Family reunification or point-based immigration system? The case of the U.S. and Mexico"

2011/20, Bogliacino, F.; Piva, M.; Vivarelli, M.: "The impact of R\&D on employment in Europe: a firm-level analysis"

2011/21, Tonello, M.: "Mechanisms of peer interactions between native and non-native students: rejection or integration?"

2011/22, García-Quevedo, J.; Mas-Verdú, F.; Montolio, D.: "What type of innovative firms acquire knowledge intensive services and from which suppliers?"

2011/23, Banal-Estañol, A.; Macho-Stadler, I.; Pérez-Castrillo, D.: "Research output from university-industry collaborative projects"

2011/24, Ligthart, J.E.; Van Oudheusden, P.: "In government we trust: the role of fiscal decentralization"

2011/25, Mongrain, S.; Wilson, J.D.: “Tax competition with heterogeneous capital mobility"

2011/26, Caruso, R.; Costa, J.; Ricciuti, R.: "The probability of military rule in Africa, 1970-2007"

2011/27, Solé-Ollé, A.; Viladecans-Marsal, E.: "Local spending and the housing boom"

2011/28, Simón, H.; Ramos, R.; Sanromá, E.: "Occupational mobility of immigrants in a low skilled economy. The Spanish case"

2011/29, Piolatto, A.; Trotin, G.: "Optimal tax enforcement under prospect theory"

2011/30, Montolio, D; Piolatto, A.: "Financing public education when altruistic agents have retirement concerns"

2011/31, García-Quevedo, J.; Pellegrino, G.; Vivarelli, M.: “The determinants of YICs' R\&D activity"

2011/32, Goodspeed, T.J.: "Corruption, accountability, and decentralization: theory and evidence from Mexico"

2011/33, Pedraja, F.; Cordero, J.M.: "Analysis of alternative proposals to reform the Spanish intergovernmental transfer system for municipalities"

2011/34, Jofre-Monseny, J.; Sorribas-Navarro, P.; Vázquez-Grenno, J.: "Welfare spending and ethnic heterogeneity: evidence from a massive immigration wave"

2011/35, Lyytikäinen, T.: "Tax competition among local governments: evidence from a property tax reform in Finland"

2011/36, Brülhart, M.; Schmidheiny, K.: "Estimating the Rivalness of State-Level Inward FDI"

2011/37, García-Pérez, J.I.; Hidalgo-Hidalgo, M.; Robles-Zurita, J.A.: "Does grade retention affect achievement? Some evidence from Pisa"

2011/38, Boffa, f.; Panzar. J.: "Bottleneck co-ownership as a regulatory alternative" 
2011/39, González-Val, R.; Olmo, J.: "Growth in a cross-section of cities: location, increasing returns or random growth?"

2011/40, Anesi, V.; De Donder, P.: "Voting under the threat of secession: accommodation vs. repression"

2011/41, Di Pietro, G.; Mora, T.: "The effect of the l'Aquila earthquake on labour market outcomes"

2011/42, Brueckner, J.K.; Neumark, D.: "Beaches, sunshine, and public-sector pay: theory and evidence on amenities and rent extraction by government workers"

2011/43, Cortés, D.: "Decentralization of government and contracting with the private sector"

2011/44, Turati, G.; Montolio, D.; Piacenza, M.: "Fiscal decentralisation, private school funding, and students' achievements. A tale from two Roman catholic countries"

2012/1, Montolio, D.; Trujillo, E.: "What drives investment in telecommunications? The role of regulation, firms' internationalization and market knowledge"

2012/2, Giesen, K.; Suedekum, J.: "The size distribution across all "cities": a unifying approach"

2012/3, Foremny, D.; Riedel, N.: "Business taxes and the electoral cycle"

2012/4, García-Estévez, J.; Duch-Brown, N.: "Student graduation: to what extent does university expenditure matter?"

2012/5, Durán-Cabré, J.M.; Esteller-Moré, A.; Salvadori, L.: "Empirical evidence on horizontal competition in tax enforcement"

2012/6, Pickering, A.C.; Rockey, J.: "Ideology and the growth of US state government"

2012/7, Vergolini, L.; Zanini, N.: "How does aid matter? The effect of financial aid on university enrolment decisions"

2012/8, Backus, P.: "Gibrat's law and legacy for non-profit organisations: a non-parametric analysis"

2012/9, Jofre-Monseny, J.; Marín-López, R.; Viladecans-Marsal, E.: "What underlies localization and urbanization economies? Evidence from the location of new firms"

2012/10, Mantovani, A.; Vandekerckhove, J.: "The strategic interplay between bundling and merging in complementary markets"

2012/11, Garcia-López, M.A.: "Urban spatial structure, suburbanization and transportation in Barcelona"

2012/12, Revelli, F.: "Business taxation and economic performance in hierarchical government structures"

2012/13, Arqué-Castells, P.; Mohnen, P.: "Sunk costs, extensive R\&D subsidies and permanent inducement effects"

2012/14, Boffa, F.; Piolatto, A.; Ponzetto, G.: "Centralization and accountability: theory and evidence from the Clean Air Act"

2012/15, Cheshire, P.C.; Hilber, C.A.L.; Kaplanis, I.: "Land use regulation and productivity - land matters: evidence from a UK supermarket chain"

2012/16, Choi, A.; Calero, J.: "The contribution of the disabled to the attainment of the Europe 2020 strategy headline targets"

2012/17, Silva, J.I.; Vázquez-Grenno, J.: "The ins and outs of unemployment in a two-tier labor market"

2012/18, González-Val, R.; Lanaspa, L.; Sanz, F.: "New evidence on Gibrat's law for cities"

2012/19, Vázquez-Grenno, J.: "Job search methods in times of crisis: native and immigrant strategies in Spain"

2012/20, Lessmann, C.: "Regional inequality and decentralization - an empirical analysis"

2012/21, Nuevo-Chiquero, A.: "Trends in shotgun marriages: the pill, the will or the cost?"

2012/22, Piil Damm, A.: "Neighborhood quality and labor market outcomes: evidence from quasi-random neighborhood assignment of immigrants"

2012/23, Ploeckl, F.: "Space, settlements, towns: the influence of geography and market access on settlement distribution and urbanization"

2012/24, Algan, Y.; Hémet, C.; Laitin, D.: "Diversity and local public goods: a natural experiment with exogenous residential allocation"

2012/25, Martinez, D.; Sjögren, T.: "Vertical externalities with lump-sum taxes: how much difference does unemployment make?"

2012/26, Cubel, M.; Sanchez-Pages, S.: "The effect of within-group inequality in a conflict against a unitary threat" 2012/27, Andini, M.; De Blasio, G.; Duranton, G.; Strange, W.C.: "Marshallian labor market pooling: evidence from Italy"

2012/28, Solé-Ollé, A.; Viladecans-Marsal, E.: "Do political parties matter for local land use policies?"

2012/29, Buonanno, P.; Durante, R.; Prarolo, G.; Vanin, P.: "Poor institutions, rich mines: resource curse and the origins of the Sicilian mafia"

2012/30, Anghel, B.; Cabrales, A.; Carro, J.M.: "Evaluating a bilingual education program in Spain: the impact beyond foreign language learning"

2012/31, Curto-Grau, M.; Solé-Ollé, A.; Sorribas-Navarro, P.: "Partisan targeting of inter-governmental transfers $\&$ state interference in local elections: evidence from Spain" 
2012/32, Kappeler, A.; Solé-Ollé, A.; Stephan, A.; Välilä, T.: "Does fiscal decentralization foster regional investment in productive infrastructure?"

2012/33, Rizzo, L.; Zanardi, A.: "Single vs double ballot and party coalitions: the impact on fiscal policy. Evidence from Italy"

2012/34, Ramachandran, R.: "Language use in education and primary schooling attainment: evidence from a natural experiment in Ethiopia"

2012/35, Rothstein, J.: "Teacher quality policy when supply matters"

2012/36, Ahlfeldt, G.M.: "The hidden dimensions of urbanity"

2012/37, Mora, T.; Gil, J.; Sicras-Mainar, A.: "The influence of BMI, obesity and overweight on medical costs: a panel data approach"

2012/38, Pelegrín, A.; García-Quevedo, J.: "Which firms are involved in foreign vertical integration?"

2012/39, Agasisti, T.; Longobardi, S.: "Inequality in education: can Italian disadvantaged students close the gap? A focus on resilience in the Italian school system"

2013/1, Sánchez-Vidal, M.; González-Val, R.; Viladecans-Marsal, E.: "Sequential city growth in the US: does age matter?"

2013/2, Hortas Rico, M.: "Sprawl, blight and the role of urban containment policies. Evidence from US cities"

2013/3, Lampón, J.F.; Cabanelas-Lorenzo, P-; Lago-Peñas, S.: "Why firms relocate their production overseas? The answer lies inside: corporate, logistic and technological determinants"

2013/4, Montolio, D.; Planells, S.: "Does tourism boost criminal activity? Evidence from a top touristic country"

2013/5, Garcia-López, M.A.; Holl, A.; Viladecans-Marsal, E.: "Suburbanization and highways: when the Romans, the Bourbons and the first cars still shape Spanish cities"

2013/6, Bosch, N.; Espasa, M.; Montolio, D.: "Should large Spanish municipalities be financially compensated? Costs and benefits of being a capital/central municipality"

2013/7, Escardíbul, J.O.; Mora, T.: "Teacher gender and student performance in mathematics. Evidence from Catalonia"

2013/8, Arqué-Castells, P.; Viladecans-Marsal, E.: "Banking towards development: evidence from the Spanish banking expansion plan"

2013/9, Asensio, J.; Gómez-Lobo, A.; Matas, A.: "How effective are policies to reduce gasoline consumption? Evaluating a quasi-natural experiment in Spain"

2013/10, Jofre-Monseny, J.: "The effects of unemployment benefits on migration in lagging regions"

2013/11, Segarra, A.; García-Quevedo, J.; Teruel, M.: "Financial constraints and the failure of innovation projects"

2013/12, Jerrim, J.; Choi, A.: "The mathematics skills of school children: How does England compare to the high performing East Asian jurisdictions?"

2013/13, González-Val, R.; Tirado-Fabregat, D.A.; Viladecans-Marsal, E.: "Market potential and city growth: Spain 1860-1960"

2013/14, Lundqvist, H.: "Is it worth it? On the returns to holding political office"

2013/15, Ahlfeldt, G.M.; Maennig, W.: "Homevoters vs. leasevoters: a spatial analysis of airport effects"

2013/16, Lampón, J.F.; Lago-Peñas, S.: "Factors behind international relocation and changes in production geography in the European automobile components industry"

2013/17, Guío, J.M.; Choi, A.: "Evolution of the school failure risk during the 2000 decade in Spain: analysis of Pisa results with a two-level logistic mode"

2013/18, Dahlby, B.; Rodden, J.: "A political economy model of the vertical fiscal gap and vertical fiscal imbalances in a federation"

2013/19, Acacia, F.; Cubel, M.: "Strategic voting and happiness"

2013/20, Hellerstein, J.K.; Kutzbach, M.J.; Neumark, D.: "Do labor market networks have an important spatial dimension?"

2013/21, Pellegrino, G.; Savona, M.: "Is money all? Financing versus knowledge and demand constraints to innovation"

2013/22, Lin, J.: "Regional resilience"

2013/23, Costa-Campi, M.T.; Duch-Brown, N.; García-Quevedo, J.: "R\&D drivers and obstacles to innovation in the energy industry"

2013/24, Huisman, R.; Stradnic, V.; Westgaard, S.: "Renewable energy and electricity prices: indirect empirical evidence from hydro power"

2013/25, Dargaud, E.; Mantovani, A.; Reggiani, C.: "The fight against cartels: a transatlantic perspective"

2013/26, Lambertini, L.; Mantovani, A.: "Feedback equilibria in a dynamic renewable resource oligopoly: preemption, voracity and exhaustion" 
2013/27, Feld, L.P.; Kalb, A.; Moessinger, M.D.; Osterloh, S.: "Sovereign bond market reactions to fiscal rules and no-bailout clauses - the Swiss experience"

2013/28, Hilber, C.A.L.; Vermeulen, W.: "The impact of supply constraints on house prices in England"

2013/29, Revelli, F.: "Tax limits and local democracy"

2013/30, Wang, R.; Wang, W.: "Dress-up contest: a dark side of fiscal decentralization"

2013/31, Dargaud, E.; Mantovani, A.; Reggiani, C.: "The fight against cartels: a transatlantic perspective"

2013/32, Saarimaa, T.; Tukiainen, J.: "Local representation and strategic voting: evidence from electoral boundary reforms"

2013/33, Agasisti, T.; Murtinu, S.: "Are we wasting public money? No! The effects of grants on Italian university students' performances"

2013/34, Flacher, D.; Harari-Kermadec, H.; Moulin, L.: "Financing higher education: a contributory scheme" 2013/35, Carozzi, F.; Repetto, L.: "Sending the pork home: birth town bias in transfers to Italian municipalities" 2013/36, Coad, A.; Frankish, J.S.; Roberts, R.G.; Storey, D.J.: "New venture survival and growth: Does the fog lift?"

2013/37, Giulietti, M.; Grossi, L.; Waterson, M.: "Revenues from storage in a competitive electricity market: Empirical evidence from Great Britain"

2014/1, Montolio, D.; Planells-Struse, S.: "When police patrols matter. The effect of police proximity on citizens' crime risk perception"

2014/2, Garcia-López, M.A.; Solé-Ollé, A.; Viladecans-Marsal, E.: "Do land use policies follow road construction?"

2014/3, Piolatto, A.; Rablen, M.D.: "Prospect theory and tax evasion: a reconsideration of the Yitzhaki puzzle"

2014/4, Cuberes, D.; González-Val, R.: "The effect of the Spanish Reconquest on Iberian Cities"

2014/5, Durán-Cabré, J.M.; Esteller-Moré, E.: "Tax professionals' view of the Spanish tax system: efficiency, equity and tax planning" 
(U)

B Universitat

de Barcelona

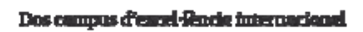
$\mathrm{BKC}=$

ieb@ub.edu

www.ieb.ub.edu 